\title{
Processing and characterization of pure cordierite and zirconia-doped cordierite ceramic composite by precipitation technique
}

\author{
M SENTHIL KUMAR ${ }^{1, *}$, A ELAYA PERUMAL ${ }^{2}$, T R VIJAYARAM ${ }^{1}$ and \\ GOVINDAN SENGUTTUVAN ${ }^{3}$ \\ ${ }^{1}$ School of Mechanical and Building Sciences, VIT University, Chennai 600 127, India \\ ${ }^{2}$ Department of Mechanical Engineering, Anna University, Chennai 600 025, India \\ ${ }^{3}$ Department of Physics, College of Engineering and Technology, Tiruchirappalli 620 024, India
}

MS received 3 January 2014; revised 1 August 2014

\begin{abstract}
Pure cordierite and cordierite- $\mathrm{ZrO}_{2}$ composite (5-20 wt \%) ceramics for various stoichiometric compositions were synthesized from standard raw materials by a novel precipitation technique. The analytical techniques such as X-ray diffraction, simultaneous thermogravimetric and differential thermal analysis, Fourier transform infrared spectroscopy, scanning electron microscopy and bulk density were employed to evaluate the properties and microstructure. Results show that the ceramic composites consist of cordierite and zircon phases. The cordieritezirconia $(20 \mathrm{wt} \%)$ increased the fracture toughness value from 3.38 to $3.94 \mathrm{MPa}$, which is mainly due to martensitic transformation present in zirconia. The flexural strength of composite was found to increase from 126.46 to 297.62 MPa. The thermal expansion coefficients of cordierite and cordierite-zirconia $(20 \mathrm{wt} \%)$ were $4.08 \times 10^{-6}$ and $4.42 \times 10^{-6}{ }^{\circ} \mathrm{C}^{-1}$ which may be due to the addition of zirconia.
\end{abstract}

Keywords. Cordierite; zirconia $\left(\mathrm{ZrO}_{2}\right)$; temperature; phase transformation; properties.

\section{Introduction}

The mechanical properties play a major role in determining the suitability of any material for specific applications in engineering applications. The desirable properties of ceramic systems are obtained by proper selection of the stoichiometric composition needed for the formation of crystalline phases. Fine-grain developed microstructure improves the thermo-mechanical properties, ${ }^{1}$ in high temperature applications like kiln furniture, molten metal filter, microelectronic components and industrial heat recovery. ${ }^{2}$ Cordierite ceramic is used increasingly in thermal-related applications due to its low thermal expansion and high refractoriness. Cordierite ceramic have lower cost of operation, chemically inert, high reliability and durability, low pressure drop, fast heating time and structural stability at high temperatures. This is a requirement for thermal shock resistance and for use in severely exhaustive environments at high temperatures. ${ }^{3}$ The impetus of cordierite research activity is mainly due to their prominence in the current market scenario.

There have been different synthesis procedures for cordierite ceramic like conventional and unconventional techniques (sol-gel, precipitation, co-precipitation, etc.). The conventional method described for synthesizing cordierite ceramic is carried out by using naturally available materials like kaolin and talc for specific application in casting ${ }^{4}$ and also by two different methods (mechanical and precipitation

\footnotetext{
*Author for correspondence (msv305@yahoo.co.in, ep_mal@yahoo.com)
}

technique) by using nonstandard raw materials kaolin, talc, feldspar, silica and sepiolite for foundry application. ${ }^{5}$ Researchers have also prepared pure cordierite powders through the sol-gel technique. ${ }^{6}$ The mechanochemical activation performed on starting materials kaolin, pyrophyllite and talcum showed synthesis by solid-state reaction occurred at lower sintering temperature, also reported low thermal expansion. ${ }^{7}$

Cordierite is not easily obtained by solid-state reactions from oxides, because of its refractory character. Synthetic powders exhibit heterogeneous surface properties and even chemical inhomogenity. Hence for better homogeneous mixture, the addition of sintering aids or impurities was introduced. The final (especially mechanical) characteristics of a ceramic body are strongly dependent on the nature of the starting powder, an improvement in the reliability and reproducibility of cordierite properties is highly desirable. The powders synthesized without sintering aid reported either very low or no improvement in mechanical properties thus proved that it is difficult to promote sintering without a sintering aid. This was due to its narrow sintering range around $1420^{\circ} \mathrm{C}$ and has its incongruent melting at $1450^{\circ} \mathrm{C}{ }^{8}$ The use of sintering aid results in lowering of the crystallization temperature and increases the thermal expansion coefficient thus making it difficult to produce a high density and high strength cordierite ceramic material.

Cordierite has relatively poor mechanical properties compared to other ceramic materials, and in order to enhance its mechanical properties, zirconia, titania, ceria, etc., have been added to the cordierite matrix as a secondary phase. The interaction between cordierite and copper and/or cerium 
oxides revealed that copper oxide had reacted at $900^{\circ} \mathrm{C}$ with the formation of a new phase (the spinel, $\mathrm{CuA}_{2} \mathrm{O}_{4}$ ); on the contrary cerium oxide does not react up to $1200^{\circ} \mathrm{C} .{ }^{9}$ Modifications in the microstructure and mechanical properties of ceria-doped cordierite have been investigated from minerals such as kaolin, talc and alumina, slurried with water and plasticizers. ${ }^{10}$ Cordierite-titania synthesized from talc and clay produced materials with reduced thermal expansion. ${ }^{11}$ Gel cast forming method using tert-butyl alcohol improved the low temperature sintering of the cordierite powder. ${ }^{12}$ Cordierite formation was observed at low sintering temperature $\left(1300^{\circ} \mathrm{C}\right)$ with the addition of $\mathrm{TiO}_{2}$ dopant. Titaniadoped cordierite exhibited better mechanical properties and low thermal expansion coefficient. The addition of the dopant showed a remarkable influence on crystallization. ${ }^{13}$

There are wide ranges of techniques available, and each requires different characteristics in the starting powder. Therefore it is essential that the production processes are capable of being controlled to produce the desired properties, and characterization techniques exist to be able to monitor them. For these reasons, an alternative method for processing by chemical route, 'precipitation process' that would yield highly reactive and better controlled cordierite particles, have been developed.

The precipitation technique using aluminium sulphate, magnesium sulphate and sodium silicate solution with zirconia powder between 15 and $35 \mathrm{wt} \%$ resulted in highly densified cordierite. The results showed good sintering characteristics with improved mechanical properties at zirconia composition of $15 \mathrm{wt} \% .^{14}$ The reports suggested that the cordierite matrix dispersed with fine zirconia $\left(\mathrm{ZrO}_{2}\right)$ increased the mechanical properties but affect the sinterability of the composites ${ }^{15}$ and the dispersion of $\mathrm{ZrO}_{2}$ particles as a second phase enhanced the mechanical properties of cordierite. ${ }^{16}$

The present research work is focused on the synthesis of highly homogeneous cordierite and cordierite-zirconia (5$20 \mathrm{wt} \%$ ) ceramic. The ceramic composites were prepared from standard raw materials by the precipitation technique, novel technique for synthesis. The physical, thermo-mechanical properties were investigated to evaluate the porosity, density, hardness, fracture toughness, flexural strength and coefficient of thermal expansion. The proposed research is carried out to examine its possibility as an alternate material for high temperature applications.

\section{Materials and methods}

\subsection{Sample preparation}

Synthesizing by precipitation technique of cordierite and cordierite-zirconia was done with a stoichiometric composition of cordierite (MgO: $13.8 \mathrm{wt} \%, \mathrm{Al}_{2} \mathrm{O}_{3}: 34.8 \mathrm{wt} \%, \mathrm{SiO}_{2}$ : $51.4 \mathrm{wt} \%$ ) and zirconia (5-20 wt\%). Oxides of the starting powders were mixed with water as the solvent and sodium hydroxide, and then precipitated with sodium carbonate and hydrochloric acid. The precipitate was filtered and washed until the presence of $\mathrm{Na}^{+}$is diminished. The precipitate was dried at $100^{\circ} \mathrm{C}$ for $12 \mathrm{~h}$. The cordierite-zirconia samples were added with zirconia (5-20 wt $\%$ ). The samples were wet milled for $3 \mathrm{~h}$ and dried at $100^{\circ} \mathrm{C}$ for $12 \mathrm{~h}$. Then it was followed by dry milling at $2 \mathrm{~h}$. The dried sample powders were added with $1 \mathrm{wt} \%$ flux. The precursor powders were then uniaxially pressed into pellets and round bars at $240 \mathrm{MPa}$ to $10 \mathrm{~mm}$ in diameter, using $1 \mathrm{wt} \%$ of polyvinyl alcohol (PVA) as a binder. The green compacts were calcined at $400^{\circ} \mathrm{C}$ for $3 \mathrm{~h}$ at a slow heating rate $2^{\circ} \mathrm{C} \mathrm{min}^{-1}$ to avoid uneven shrinkage, bending and to burnout the binder. The calcined compacts were sintered at different temperatures between 1000 and $1350^{\circ} \mathrm{C}$ for $3 \mathrm{~h}$.

\subsection{Characterization}

The prepared samples were characterized by diffractometer (XRD 3000, SEIFERT) with a graphite monochromatic $\mathrm{Cu}-\mathrm{K} \alpha$ radiation of $1.5406 \AA$ operating at $30 \mathrm{kV}$ and 40 $\mathrm{mA}$ to study the X-ray powder diffraction (XRD). The XRD patterns were acquired in the $2 \theta$ range of $5-70^{\circ}$ to determine the phase evolution at different sintering temperatures. The thermogravimetric and differential thermal analysis (TG/DTA) curve was obtained from the thermal analyzer (NETZSCH STA 409 C/CD TG/DTA Instrument) at a heating rate of $10^{\circ} \mathrm{C} \mathrm{min}^{-1}$, to study the thermal decomposition and phase evolution of the dried powders. The structural deformation and bonding nature of the heat-treated powders, obtained by the Fourier transform infrared (FTIR) spectrometer (BRUKER RFS27) in potassium bromide (KBr) medium were recorded in the range $4000-50 \mathrm{~cm}^{-1}$ are explained.

\subsection{Sintering and microstructure}

The samples were sintered for $3 \mathrm{~h}$ in air at different temperatures ranging from 1000 to $1350^{\circ} \mathrm{C}$. The heating rate was chosen as $10^{\circ} \mathrm{C} \mathrm{min}^{-1}$ up to the sintering temperatures for all samples. Natural cooling $\left(5^{\circ} \mathrm{C} \mathrm{min}^{-1}\right)$ was maintained after the soaking period. The density of the sintered samples was determined by applying the Archimedes principle and porosity analysis was carried out by using computer integrated image analyser. The sintered samples were then polished by using different grades of polishing sheets (1/0-4/0). The mirror polished specimens were thermally etched at $1200^{\circ} \mathrm{C}$ for $30 \mathrm{~min}$. Finally, the polished powders were subjected to study the morphological features by means of the scanning electron microscope (SEM HITACHI-S3400N) micrographs.

\subsection{Thermo-mechanical properties}

Hardness measurement was carried out on thermally etched samples by the Vickers indentation technique (Model ZWICK 3212) for a standard load of $98 \mathrm{~N}^{13}$ in the microhardness tester. The fracture toughness $\left(K_{\mathrm{IC}}\right)$ was evaluated by using the indentation fracture method. The $K_{\text {IC }}$ of the ceramics was estimated for a load $(98 \mathrm{~N})$, for $15 \mathrm{~s}$ as the holding time experimentally, using the following formula ${ }^{17}$ with a 


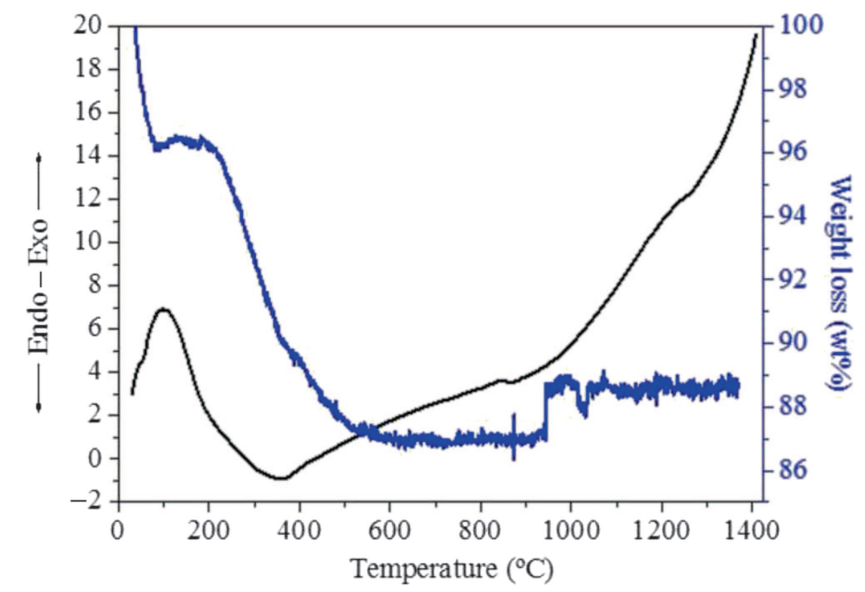

Figure 1. TG/DTA curve for pure cordierite sample dried at $100^{\circ} \mathrm{C}$.

Vickers indenter:

$$
K_{\mathrm{IC}}=(0.0319 \times P) / a l^{1 / 2}
$$

where $P$ is the indentation force $(\mathrm{N}), c$ the crack length (m) and $a$ the half-length of the diagonal (m), $l=c-a$, as described in figure 1.

The flexural strength was measured by using 5 samples in each composition prepared with a span length of a $25 \mathrm{~mm}$ long. The measurements were performed using the threepoint bending technique, using a universal testing machine (Model Unitek-94100, Fuel instrument and Engineers). The cross head speed in loading was $0.5 \mathrm{~mm} \mathrm{~min}^{-1}$. The thermomechanical analysis was carried out by using a dilatometer (Model Dil/1400C, VB Ceramics). The coefficient of thermal expansion was measured at a heating rate of $10^{\circ} \mathrm{C} \mathrm{min}-1$ from 70 to $800^{\circ} \mathrm{C}$.

\section{Results and discussion}

\subsection{Characterization studies for cordierite and cordierite- zirconia ceramic samples}

The characterization results for the samples of cordierite and cordierite-zirconia (5-20 wt\%) ceramic composite, at different sintering temperatures are shown in table 1 . The results exhibited the importance of sintering temperature in the synthesis of cordierite and cordierite-zirconia samples. Further, the results revealed the phase transformations at different temperatures. It also confirmed the presence of pure cordierite as a primary phase and zircon as a secondary phase in the cordierite-zirconia samples.

3.1a Thermal evaluation (TGA/DTA): The cordierite powder sample was subjected to TG/DTA analysis and the curve obtained is shown in figure 1 . Two endothermic peaks were observed in two regions in the pure cordierite sample
Table 1. Phase evolution of samples at various sintering temperatures.

\begin{tabular}{|c|c|c|c|c|c|}
\hline \multirow[b]{2}{*}{ Sample } & \multicolumn{5}{|c|}{ Phase composition } \\
\hline & $600^{\circ} \mathrm{C}$ & $800^{\circ} \mathrm{C}$ & $1000^{\circ} \mathrm{C}$ & $1200^{\circ} \mathrm{C}$ & $1350^{\circ} \mathrm{C}$ \\
\hline Cordierite & A & MAS & $\begin{array}{c}\mu-C \\
S \\
C\end{array}$ & $\begin{array}{c}\mu-C \\
\alpha-C \\
S \\
C\end{array}$ & $\alpha-\mathrm{C}$ \\
\hline $\begin{array}{l}\text { Cordierite-zirconia } \\
(5 \mathrm{wt} \%)\end{array}$ & A & MAS & $\begin{array}{c}\mu-C \\
S \\
C \\
\text { t-Zir }\end{array}$ & $\begin{array}{c}\mu-C \\
\alpha-C \\
S \\
C \\
t-Z\end{array}$ & $\begin{array}{c}\alpha-C \\
Z\end{array}$ \\
\hline $\begin{array}{l}\text { Cordierite-zirconia } \\
(10 \mathrm{wt} \%)\end{array}$ & A & MAS & $\begin{array}{c}\mu-\mathrm{C} \\
\mathrm{S} \\
\mathrm{C} \\
\mathrm{t}-\mathrm{Zir}\end{array}$ & $\begin{array}{c}\mu-C \\
\alpha-C \\
S \\
C \\
t-Z\end{array}$ & $\begin{array}{c}\alpha-\mathrm{C} \\
\mathrm{Z}\end{array}$ \\
\hline $\begin{array}{l}\text { Cordierite-zirconia } \\
(15 \mathrm{wt} \%)\end{array}$ & A & MAS & $\begin{array}{c}\mu-C \\
S \\
C \\
\text { t-Zir }\end{array}$ & $\begin{array}{c}\mu-C \\
\alpha-C \\
S \\
C \\
t-Z\end{array}$ & $\begin{array}{c}\alpha-C \\
Z\end{array}$ \\
\hline $\begin{array}{l}\text { Cordierite-zirconia } \\
(20 \mathrm{wt} \%)\end{array}$ & A & MAS & $\begin{array}{c}\mu-C \\
S \\
C \\
\text { t-Zir }\end{array}$ & $\begin{array}{c}\mu-C \\
\alpha-C \\
S \\
C \\
t-Z\end{array}$ & $\begin{array}{c}\alpha-C \\
Z\end{array}$ \\
\hline
\end{tabular}

A-amorphous; MAS—magnesium aluminium silicate; $\mu-\mathrm{C}-$ cordierite (metastable); $\mathrm{S}$-spinel; $\mathrm{C}$-cristobalite; $\mathrm{Z}$-zircon; t-Zir-tetragonal zirconia; $\alpha-\mathrm{C}$-cordierite (stable).

(PCZr0). The first weight loss was observed in the temperature range between 150 and $250^{\circ} \mathrm{C}$, it indicated the release of physically absorbed water and the second weight loss at $500^{\circ} \mathrm{C}$ was due to the dehydration of alumina. ${ }^{12}$ The exothermic peak between 800 and $850^{\circ} \mathrm{C}$ indicated the initiation of solid-state reaction that leads to phase transformation. The second exothermic peak between 897 and $964^{\circ} \mathrm{C}$ and the third peak at $1332^{\circ} \mathrm{C}^{18,19}$ confirmed the formation of an intermediate phase ( $\mu$-cordierite) and final phase $(\alpha-$ cordierite), respectively.

TG/DTA analysis revealed that the cordierite-zirconia (PCZr5-PCZr20) samples were decomposed in the temperature range of $500-900^{\circ} \mathrm{C}$. The TG/DTA curve for cordieritezirconia (PCZr20) shown in figure 2 exhibited an exothermic peak between 750 and $800^{\circ} \mathrm{C}$, which confirmed the presence of the solid-state reaction. The second exothermic peak around $950-1100^{\circ} \mathrm{C}$ may be due to the crystallization of the amorphous phase to intermediate phase $(\mu \text {-cordierite })^{12}$ and the final transformation phase ( $\alpha$-cordierite). ${ }^{18}$ The results 


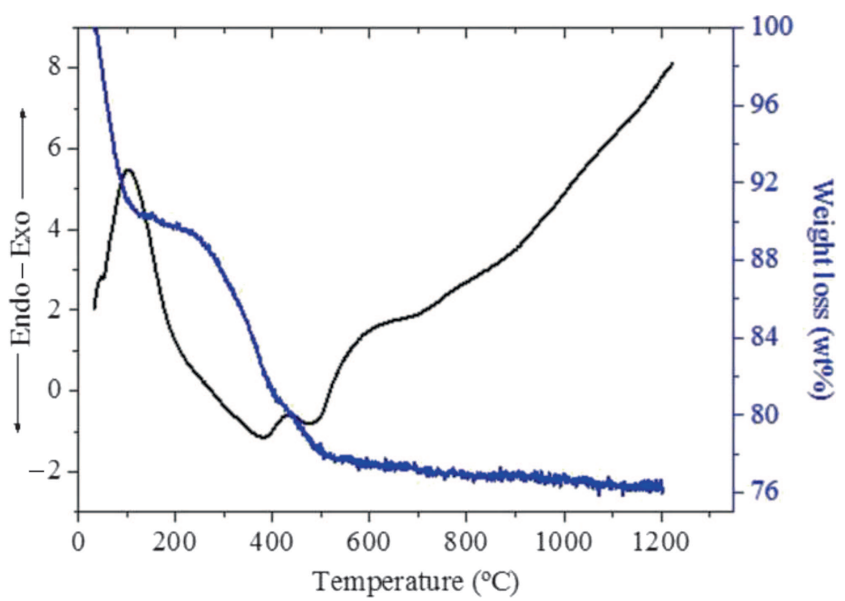

Figure 2. TG/DTA curve for cordierite-zirconia (PCZr20) sample dried at $100^{\circ} \mathrm{C}$.

show the formation of cordierite at temperature lesser than the crystallization temperature.

The above results were in agreement with the results of previous research work,${ }^{20}$ that reported the crystalline phase of cordierite phase transformation. The precursor powders were heat treated up to $1200^{\circ} \mathrm{C}$ for different series of DTA curves. The crystallization began between 929 and $1100^{\circ} \mathrm{C}$; the first peak at 929 to $934^{\circ} \mathrm{C}$ is due to the formation of the metastable phase of stuffed $\beta$-quartz, and the second peak is due to a trace amount of spinel. The third exothermic peak is due to the phase transformation of stuffed $\alpha$-quartz to $\mu$-cordierite.

3.1b FTIR characterization: Figure 3 shows the FTIR spectrum for pure cordierite powder $(\mathrm{PCZr} 0)$. At $100^{\circ} \mathrm{C}$, the absorption band of $\mathrm{SiOH}$ and/or $\mathrm{AlOH}$ group at $813 \mathrm{~cm}^{-1}$ diminished with the increase in temperature. It indicated that the condensation rate proceeds with heating. The absorption intensity of the $\mathrm{AlO}_{4}$ band was found to be increasing with temperature. It is also observed that the $\mathrm{Si}-\mathrm{O}-\mathrm{Al}$ band at $1086 \mathrm{~cm}^{-1}$ also shifts to a lower wave number. From the experimental results, it is apparent that $\mathrm{AlO}_{6}$ transformed into $\mathrm{AlO}_{4}$ during precursor heating. ${ }^{21}$ The aluminium ions get incorporated into $\mathrm{SiO}_{4}$ tetrahedral unit to form a $\mathrm{Si}-\mathrm{O}-\mathrm{Al}$ network structure. ${ }^{21}$

FTIR spectra of the cordierite powder at $1200^{\circ} \mathrm{C}$ show peaks at 1079, 956 and $486 \mathrm{~cm}^{-1}$, which is typical for the adsorption bands of silica bonds and $\mu$-cordierite. ${ }^{22}$ The band near $1100 \mathrm{~cm}^{-1}$ is due to stretched bond motion of $\mathrm{Si}$ atom against its tetrahedral oxygen cage, while the band near 486 $\mathrm{cm}^{-1}$ correspond to a symmetric motion of bridged oxygen in the plane bisecting the $\mathrm{Si}-\mathrm{O}-\mathrm{Si}$ bond. ${ }^{23}$

The presence of non-bridged oxygen in the vibration mode in alumino-silicate at $\mathrm{Mg}$ content is observed in band at $945 \mathrm{~cm}^{-1} .^{24}$ The absorption band at $740 \mathrm{~cm}^{-1}$ corresponds to the stretched vibration modes of $\mathrm{Al}-\mathrm{O}$ and $\mathrm{Mg}-\mathrm{O}$ bonds. ${ }^{25}$ The spectra of the powder heat treated at $1200^{\circ} \mathrm{C}$ correspond to a mixture of solid solution and spinel phase. The existence

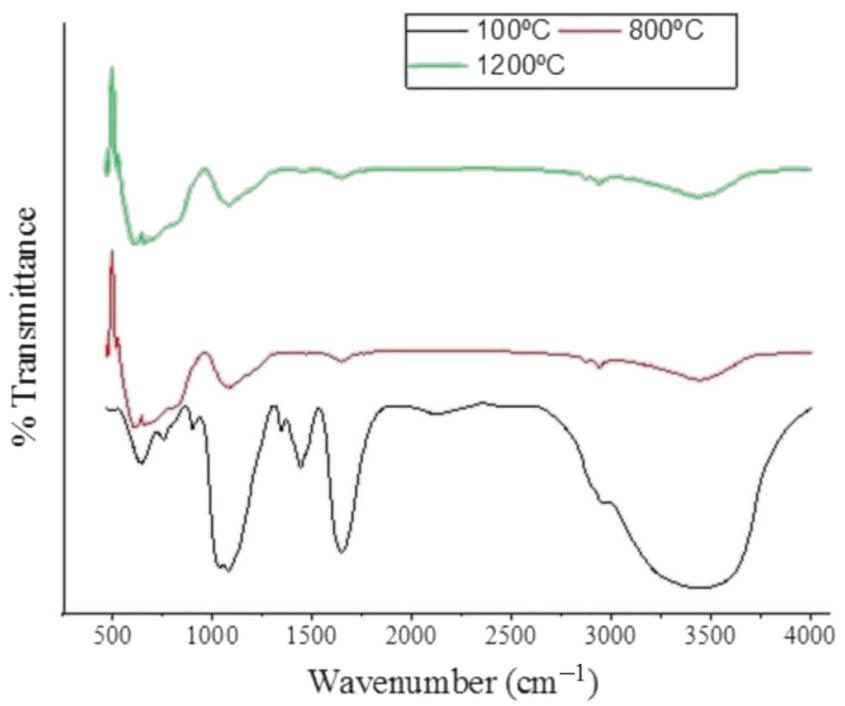

Figure 3. FTIR spectrum of pure cordierite sample at different sintering temperatures.

of spinel is evident due to the presence of bands at 650 and $550 \mathrm{~cm}^{-1} .{ }^{26}$ The absorption bands at 1080 and $776 \mathrm{~cm}^{-1}$ were due to the presence of hexagonal $\beta$-quartz and $\mu$ cordierite at higher sintering temperature. ${ }^{27}$

Figure 4 shows FTIR spectrum of the cordierite-zirconia (PCZr20) sample at different sintering temperatures. The presence of $\mathrm{Si}-\mathrm{O}-\mathrm{Si}$ in asymmetric stretched mode due to vibrations observed in bands at 900, 1010 and $1100 \mathrm{~cm}^{-1}$ for the sample calcined at $100^{\circ} \mathrm{C}$. Symmetric stretching of $\mathrm{AlO}_{4}$ tetrahedra occurred at band $1300 \mathrm{~cm}^{-1}$. It should be the band at around $740 \mathrm{~cm}^{-1}$ at $100^{\circ} \mathrm{C}$ was due to the symmetric stretching mode of the $\mathrm{Si}-\mathrm{O}-\mathrm{Si}$ bond in the sample. The band at 700 and $760 \mathrm{~cm}^{-1}$ shows the vibration mode of $\mathrm{Al}-\mathrm{O}$ or $\mathrm{Mg}-\mathrm{O}$, also the band at $1090 \mathrm{~cm}^{-1}$ corresponds to $\mathrm{AlO}_{4}$ tetrahedra. The band between 1090 and $1270 \mathrm{~cm}^{-1}$ confirms the presence of $\mathrm{SiO}_{4}$ at $800^{\circ} \mathrm{C}$. The presence of $\mu$-cordierite and $\alpha$-cordierite is confirmed at bands 1300 , 1100,870 and $580 \mathrm{~cm}^{-1}$ at $1200^{\circ} \mathrm{C}$. The presence of $\mathrm{ZrO}_{2}$ is confirmed at $530 \mathrm{~cm}^{-1} .28$ The results of FTIR samples were consistent with X-ray diffraction results. The studied adsorption bands reveal the results of the IR spectrum of cordierite samples at different temperatures. At lower temperatures, these bands were similar to the spectrum of cordierite glass. The sample heated at 1000 and $1100^{\circ} \mathrm{C}$ shows the vibration of $\mathrm{M}-\mathrm{O}$ bonds $(\mathrm{M}=\mathrm{A} 1, \mathrm{Mg}$ ) indicating $\mathrm{Si}-\mathrm{O}-\mathrm{M}$ bonding. On further heating at $1200^{\circ} \mathrm{C}$, the band at $780 \mathrm{~cm}^{-1}$ corresponding to the ring structure of the $\mathrm{SiO}_{4}$ tetrahedron appears. ${ }^{24}$

3.1c Phase evolution $(X R D)$ : Figure 5 shows XRD patterns for the pure cordierite ( $\mathrm{PCZr0}$ ) sample at different sintering temperatures. The results reveal that the sintering temperature as an important parameter in the synthesis. The XRD results for pure cordierite sample indicated the presence of a metastable $\mu$-cordierite at low sintering 


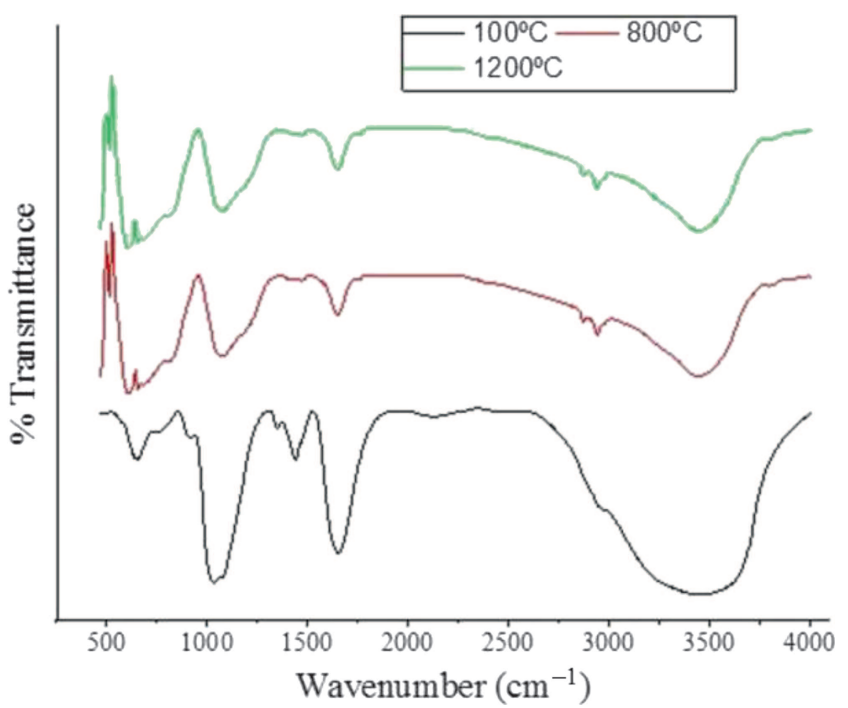

Figure 4. FTIR spectrum of cordierite-zirconia (PCZr20) samples at different sintering temperatures.

temperatures and a stable high-temperature $\alpha$-cordierite as a major constituent phase in all the samples. The $\mu$-cordierite is present as a glassy phase in the metastable state. It is observed in the temperature range between 800 and $1200^{\circ} \mathrm{C}$. The complete transformation of $\alpha$-cordierite phase was observed at $1350^{\circ} \mathrm{C} .^{19}$

The XRD results of cordierite-zirconia (PCZr20) are shown in figure 6 . The results were found to be identical with pure cordierite, that is formation of $\alpha$-cordierite phase. In addition to the $\alpha$-cordierite phase, $\mathrm{ZrSiO}_{4}$ formation is due to the reaction of $\mathrm{ZrO}_{2}$ with $\mathrm{SiO}_{2}$ at $1350^{\circ} \mathrm{C}$. The presence of $\alpha$-cordierite and zircon at sintering temperature of $1350^{\circ} \mathrm{C}$ for $3 \mathrm{~h}$ has a significant effect. The purpose of the addition of zirconia to form a secondary phase is the basis for this research to study the improvement in mechanical properties.

The XRD interpretation for cordierite ceramics prepared from mixtures of clay minerals studied at $1300^{\circ} \mathrm{C}$. This illustrated the presence of the main phase cordierite and the secondary crystalline phases. ${ }^{29}$ The cordierite samples sintered at 1300 and $1350^{\circ} \mathrm{C}$ for $1 \mathrm{~h}$ indicated ${ }^{30}$ the presence of cordierite. Significant amounts of cristobalite, spinel and traces of corundum were also reported. The sintering at $1400^{\circ} \mathrm{C}$ for $1 \mathrm{~h}$ exhibited the complete disappearance of cristobalite, spinel and corundum. For the increased sintering time of 3 and $5 \mathrm{~h}$, similar results were observed for the samples sintered at $1350^{\circ} \mathrm{C}$.

\subsection{Thermo-mechanical, physical property studies for cordierite and cordierite-zirconia ceramic samples}

The results of thermal and mechanical properties of the cordierite and cordierite-zirconia composites sintered at various sintering temperatures up to $1350^{\circ} \mathrm{C}$ are discussed in the following sections.

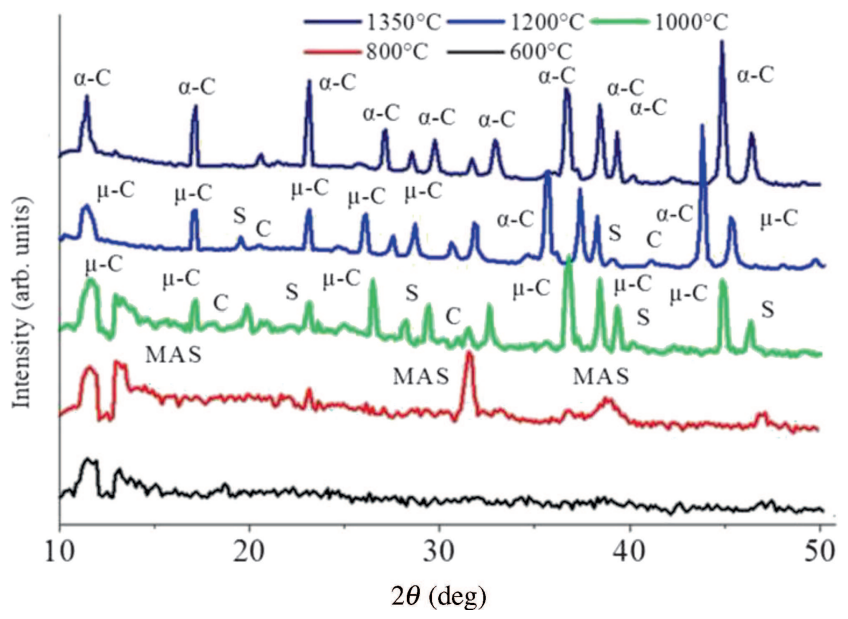

Figure 5. XRD patterns for pure cordierite (PCZr0).

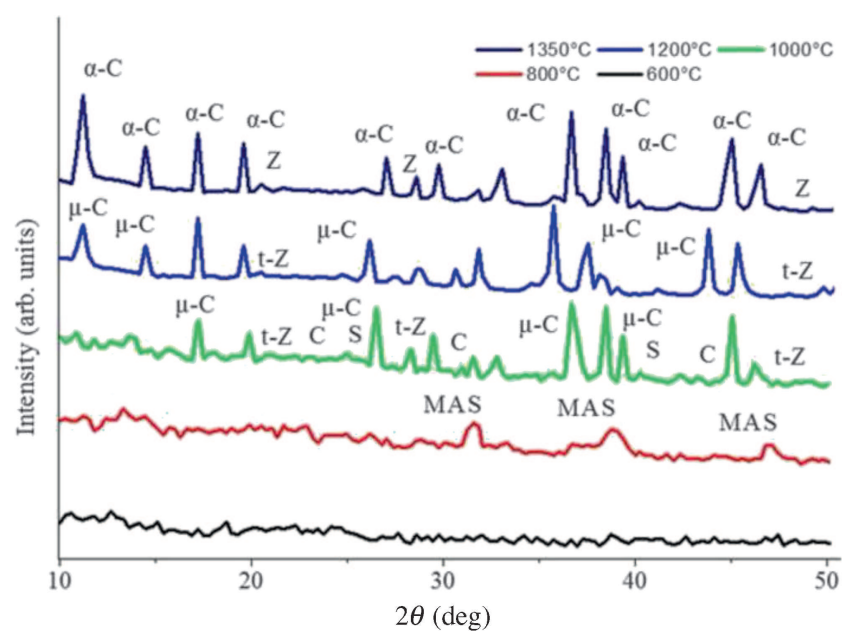

Figure 6. XRD patterns for cordierite-zirconia (PCZr20).

3.2a Bulk density and porosity: The bulk density of the cordierite compacts prepared by the precipitation and conventional route densified rapidly between 1000 and $1100^{\circ} \mathrm{C}$ (figure 7). Since, the crystallization of spinel occurs because of the intimately mixed $\mathrm{Al}^{3+}$ and $\mathrm{Mg}^{2+}$ ions, densification has occurred by the formation of some viscous liquid within a very short temperature range. The curve indicates that the densification of cordierite powder stops at the onset of the crystallization of $\mu$-cordierite. The crystallization of cordierite takes place when the compacts are fired for longer duration of time. It should be noted that in order to obtain denser products, sintering of the compacts must precede crystallization as the reverse would greatly decrease the mobility of the ions and impede sinterability. In this case, crystallization of cordierite takes place after the compacts have sintered completely.

The cordierite exhibited abrupt densification in this temperature range. ${ }^{31,32}$ However, by increasing the sintering temperature further, densification stopped. The amorphous 
silica component crystallizes to $\alpha$-quartz. At sintering temperatures above $1100^{\circ} \mathrm{C}$ resulted in decrease in densification up to $1350^{\circ} \mathrm{C}$. This shows the complete transformation of $\alpha$-cordierite. For the samples prepared by precipitation and conventional method at consolidation temperature reported a similar result. The cordierite pellets sintered above $1300^{\circ} \mathrm{C}$, reported increase in vapour pressure of the water. It expands the cavities and pores within the compacts. This makes it difficult to locate the temperature range. The densification was achieved without a detectable crystallization. The moderate densities were developed in samples. ${ }^{33,34}$ The results of porosity analysis (figures 7 and 8 ) for pure cordierite by the precipitation technique has confirmed, that the porosity decrease was evident up to $1100^{\circ} \mathrm{C}$ and on further heating porosity was found to increase. The results confirm that bulk density of samples decreased slightly (figure 7). The result of

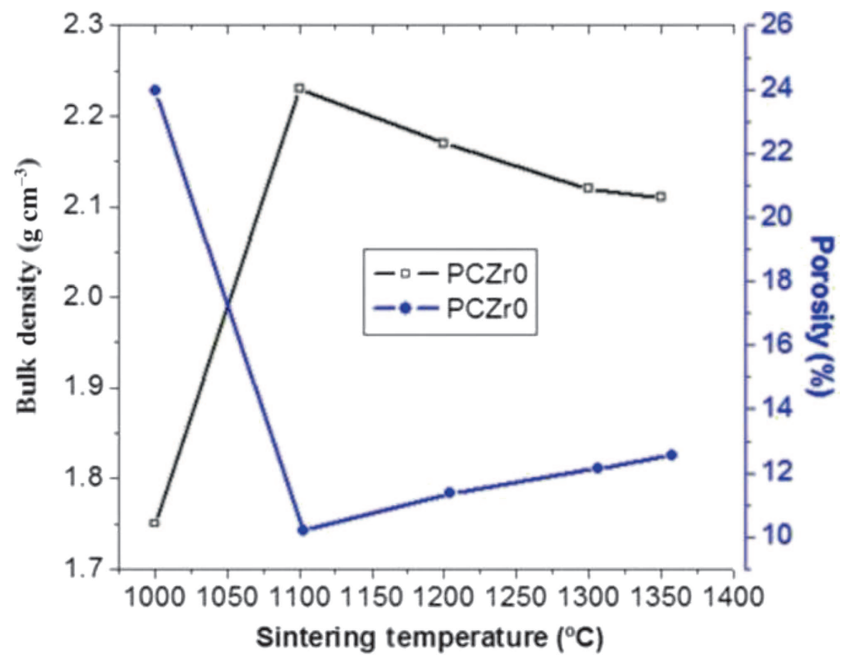

Figure 7. Bulk density and porosity of pure cordierite at different sintering temperatures. porosity analysis is also in agreement with the densification results of the sample PCZr0.

Figure 9 shows that for a given zirconia content ( $\mathrm{PCZr05}$ PCZr20) the density increased with sintering temperature. Further, at a given sintering temperature, the density increased with zirconia content in the cordierite-zirconia composite. The results exhibit that the densification temperature reduces by the addition of zirconia. The bulk density of the composites slightly increased with the increase in zirconia content in all series of composite samples. The ceramic containing $20 \mathrm{wt} \%$ of zirconia (PCZr20) shows the maximum bulk density.

The cordierite samples in the presence of $\mathrm{ZrO}_{2}$ reported the enhanced densification. ${ }^{35,36}$ The sample PCZr20 in this research showed that the bulk density increased with the increase in temperature. Further with the increased amount of zirconia content. During the sintering of the cordieritezirconia composites, two processes occur, namely densification and the formation of spinel and zircon phases. Following is the reaction at the sintering temperature for cordieritezirconia composites containing 15 and $20 \mathrm{wt} \%$ of zirconia, forming zircon and spinel between cordierite and zirconia:

$$
\mathrm{Mg}_{2} \mathrm{Al}_{4} \mathrm{Si}_{5} \mathrm{O}_{18}+5 \mathrm{ZrO}_{2} \rightarrow 5 \mathrm{ZrSiO}_{4}+2 \mathrm{MgAl}_{2} \mathrm{O}_{3} \text {. }
$$

It is observed from the X-ray diffraction patterns (figure 6) of all present samples, that the intensity of the zircon phase is slightly higher by the increased amount of $\mathrm{ZrO}_{2}$ with an increase in the sintering temperature. It is obvious that the discrepancies in the densities of all series of cordieritezirconia ceramic, are due to the formation of zircon with the presence of $\mathrm{t}-\mathrm{ZrO}_{2}$ in the matrix. The above results have been verified from the studies of porosity analysis for zirconia-doped cordierite (PCZr20) samples by the precipitation technique shown in figure 10 . The porosity decreased with increase in the sintering temperature, and shows that the
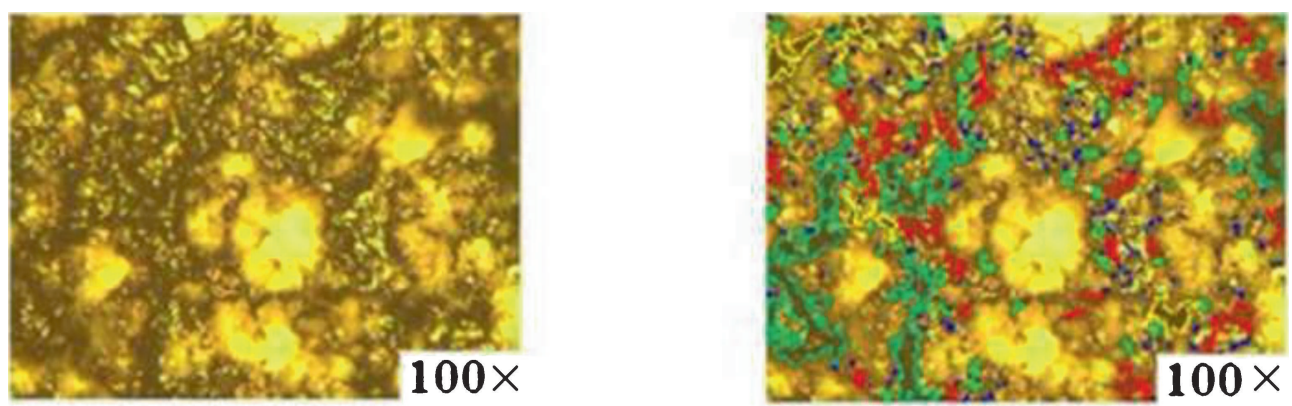

Porosity analysis: results sumuary

Fields messured
Total area
Porosity
Pores $\left(\mathrm{mm}^{2}\right)$
Standard

1 $4134\left(\mathrm{~mm}^{2}\right)$ $12.7458 \%$ 8344732 ASTM B 276

Figure 8. Porosity analysis of pure cordierite at $1350^{\circ} \mathrm{C}$. 


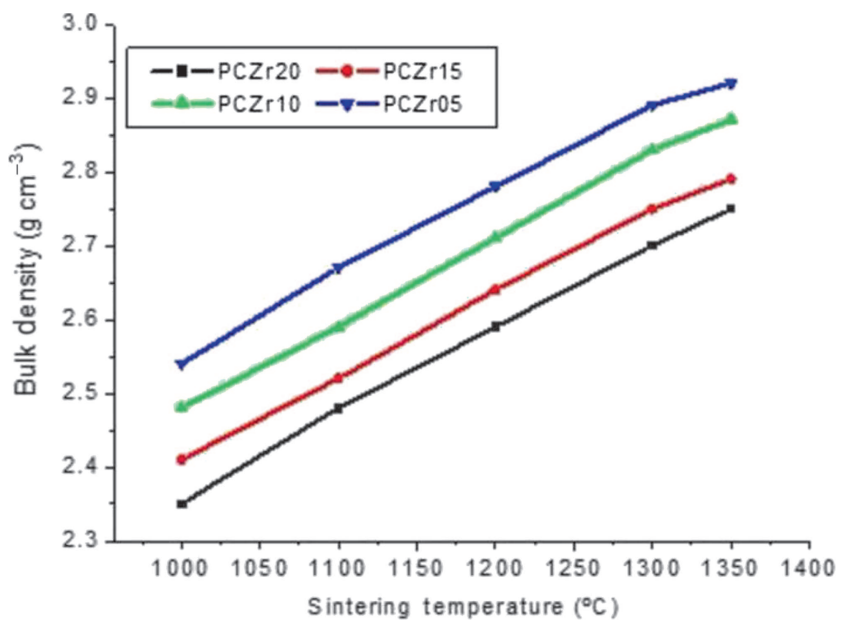

Figure 9. Bulk density of cordierite-zirconia at different sintering temperatures.

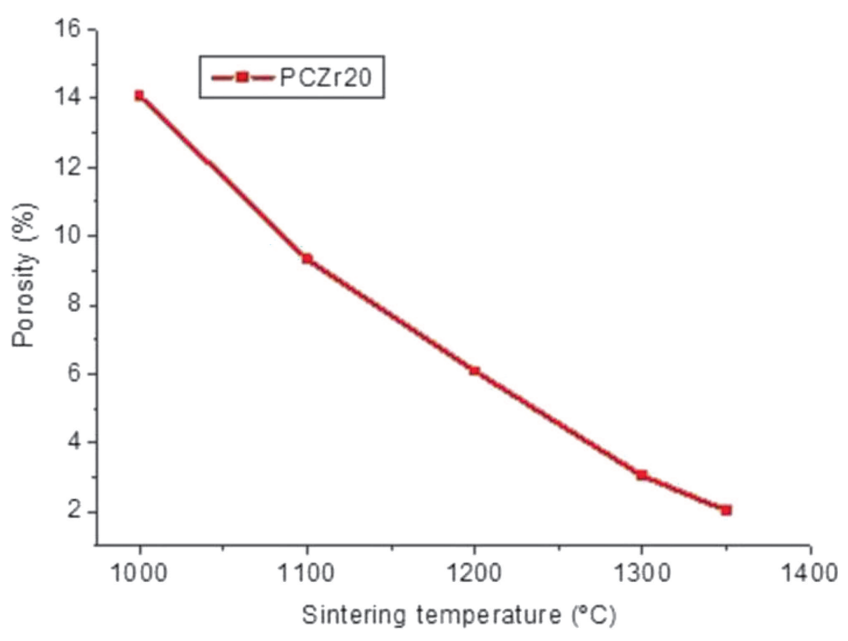

Figure 10. Porosity of cordierite-zirconia (PCZr20) at different sintering temperatures.

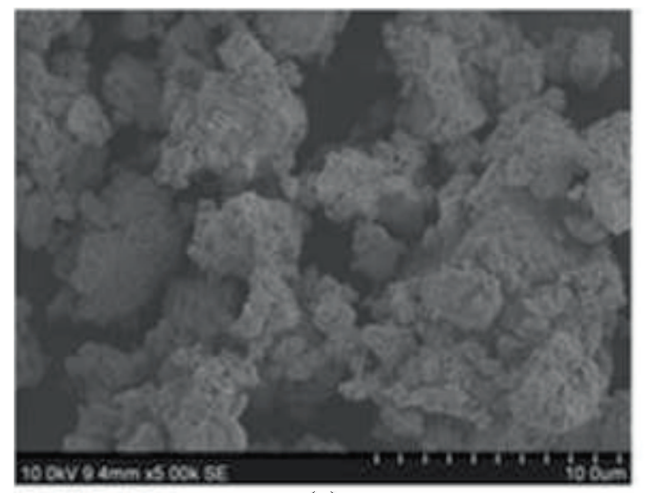

(a)

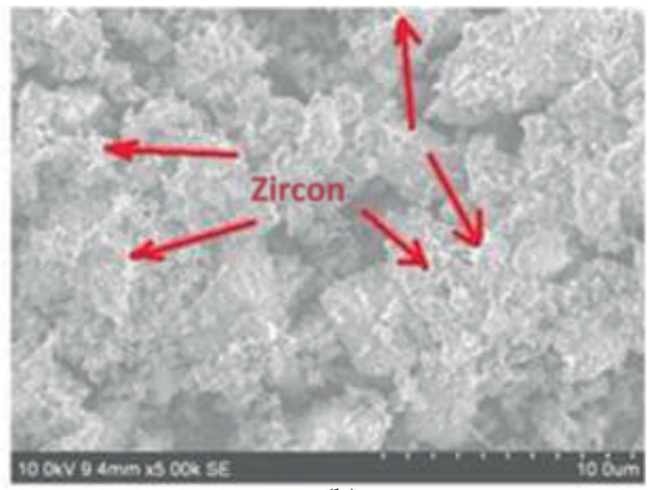

(b)

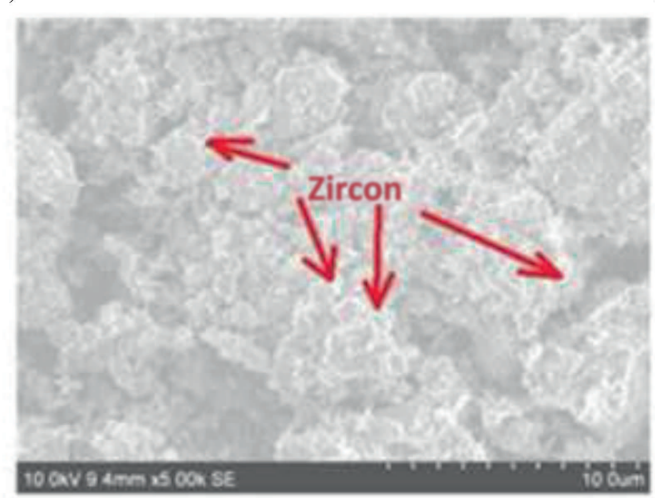

(c)

Figure 11. SEM photographs of ceramic samples sintered at $1350^{\circ} \mathrm{C}$ : (a) $\mathrm{PCZr} 0$, (b) $\mathrm{PCZr} 20$ and (c) PCZr20.

good densification results are obtained. The sample PCZr20 reported the lowest porosity, which showed good densification. This shows that porosity is in the opposite trend to the bulk density. The porosities of the PCZr20 sample sintered at $1350^{\circ} \mathrm{C}$ are very less.

3.2b Microstructural studies: Figure 11a shows the photomicrograph of cordierite specimen, which displays the surface morphology of a sintered cordierite compact with an appreciable amount of porosity. This is in agreement with the measured density. In addition, the micrograph reveals the different sizes of the grains, that densification begins by liquid phase sintering or a viscous flow mechanism prior to crystallization. It is interesting to note that the initial cordierite grain does not change its size and the corners remain sharp, indicating that little dissolution and precipitation take place 
during densification. The densification of cordierite ceramics in this study is concluded to be achieved in the first stage of liquid-phase sintering, i.e., melt redistribution and particle rearrangement. It is also interesting to note that the roundshaped cristobalite particles observed in the sample PCZrO. They began to disappear with increasing cordierite formation. This inhibition occurs as a result of the formation of a reaction layer around each alumina particle in the cordierite.

Figure $11 \mathrm{~b}$ and $\mathrm{c}$ reveals the photomicrograph of cordierite-zirconia composites (PCZr05 and PCZr20) containing 5 and $20 \mathrm{wt} \%$ of zirconia sintered at $1350^{\circ} \mathrm{C}$. The microstructure of the composite samples shows a uniform spatial distribution of the dispersed zirconia particles in the cordierite matrix, which demonstrates the advantages of the precipitation processing route, characterized by varioussized grain morphology with the presence of micro-pores and grain boundaries. The existing pores at the grain boundaries in early and intermediate stages are pulled together to form a large pore in the final stage of sintering. The XRD pattern shows the presence of both zircon and t-zirconia phases, but in the SEM, no clear distinction between the zircon and zirconia particles is observed.

3.2c Hardness determination: Figure 12 shows the Vickers hardness values of pure cordierite samples ( $\mathrm{PCZr} 0)$ for an applied load of $98 \mathrm{~N}$ as a function of the sintering temperature. The hardness of pure cordierite $(\mathrm{PCZr} 0)$ showed an increase in hardness up to $1100^{\circ} \mathrm{C}$ due to the formation of $\mu$-cordierite at this temperature. The hardness was found to decrease with sintering temperature above $1100^{\circ} \mathrm{C}$. This could be due to the formation of $\alpha$-cordierite and spinel phases. The Vickers hardness of cordierite sample sintered at $1350^{\circ} \mathrm{C}$ was found to be $6.91 \mathrm{GPa}^{37}$

The zirconia-doped cordierite samples sintered at $1350^{\circ} \mathrm{C}$ showed that the hardness increased with the increase in the sintering temperature and also with increase in the zirconia content ( $\mathrm{CZr} 05-\mathrm{CZr} 20)$ as shown in figure 12. The toughening of oxide by dispersion in ceramics by a secondary phase is a well-established process, and has been successfully employed to improve the mechanical properties. Hence, zirconia added with cordierite, forms zircon as a secondary phase. This shows that the hardness value of cordieritezirconia $(20 \mathrm{wt} \%$ ) is found to be $7.68 \mathrm{GPa}$, which showed an increase from 7.06 to $7.68 \mathrm{GPa}$. This is an expected result in the ceramics as the crystalline phases are usually harder. However, the research on cordierite and cordieritezirconia synthesized by the precipitation technique tried with the addition of a different binder (carboxymethyl cellulose) also exhibited better results. ${ }^{38}$

3.2d Fracture toughness estimation: Figure 13 shows the fracture toughness of pure cordierite (PCZr0) sample heat treated at different temperature. The fracture toughness of pure cordierite material is high $\left(K_{\mathrm{IC}}=2.94 \mathrm{MPa} \mathrm{m} \mathrm{m}^{1 / 2}\right)$ at 1100 and above $1100^{\circ} \mathrm{C}$. There is a decrease in fracture toughness value of $2.73 \mathrm{MPa} \mathrm{m} \mathrm{m}^{1 / 2}$. This may be due

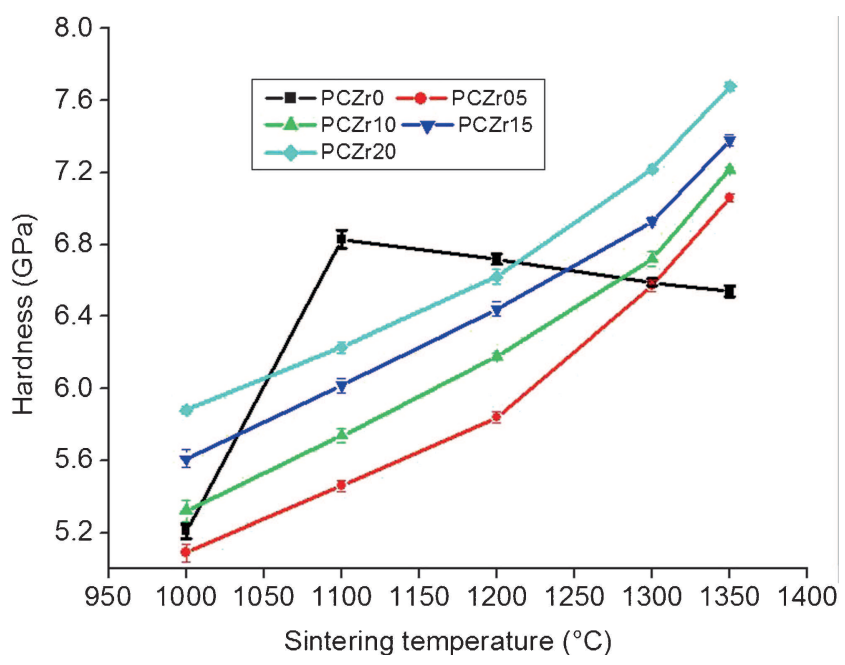

Figure 12. Vickers hardness of pure cordierite and cordieritezirconia sintered at different temperatures.

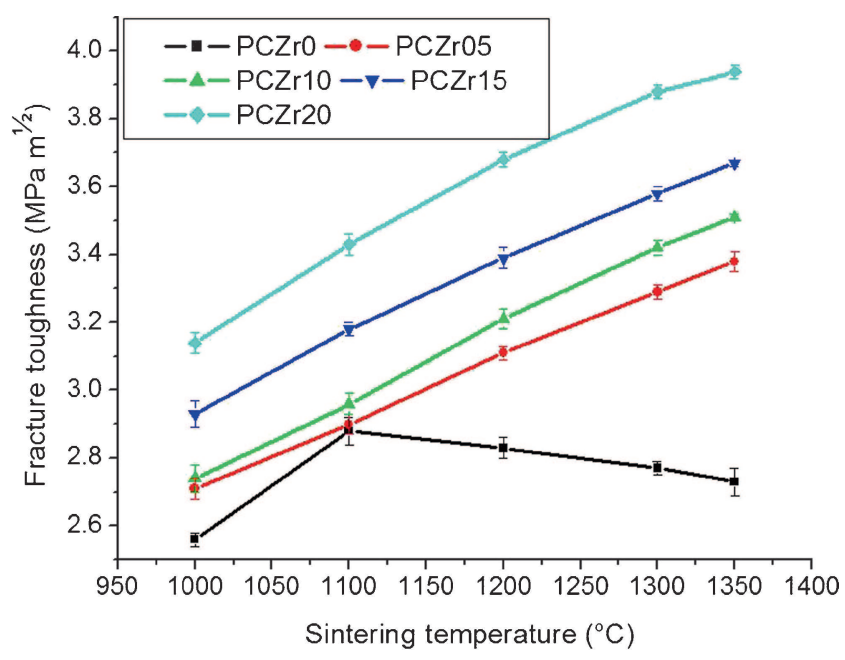

Figure 13. Fracture toughness of pure cordierite and cordieritezirconia sintered at different temperatures.

to the formation of $\alpha$-cordierite above $1000^{\circ} \mathrm{C}$. Higher grain growth results in lowering of the fracture toughness above the sintering temperature at $1200^{\circ} \mathrm{C}$.

The fracture toughness of the cordierite is enhanced with the addition of $\mathrm{ZrO}_{2}$ (5-20 wt\%). Generally, toughening of ceramics with the addition of $\mathrm{ZrO}_{2}$ can be achieved through martensitic transformation from tetragonal to monoclinic phase with $\mathrm{t}-\mathrm{ZrO}_{2}$. There were no $\mathrm{ZrO}_{2}$ and cordierite to form $\mathrm{ZrSiO}_{4}$ phase, as confirmed by the XRD analysis (figure 6). The fracture toughness of the cordierite-zirconia composites is shown in figure 13 .

The fracture toughness of the cordierite-zirconia ceramic is higher at $1350^{\circ} \mathrm{C}$. This may be due to the decrease in the $\mathrm{t}-\mathrm{ZrO}_{2}$ phases. The toughening was partly attributed to the residual compressive stresses imposed on the cordierite due to thermal expansion mismatch between cordierite and $\mathrm{ZrSiO}_{4}$ particles, especially at higher amount of stabilized 


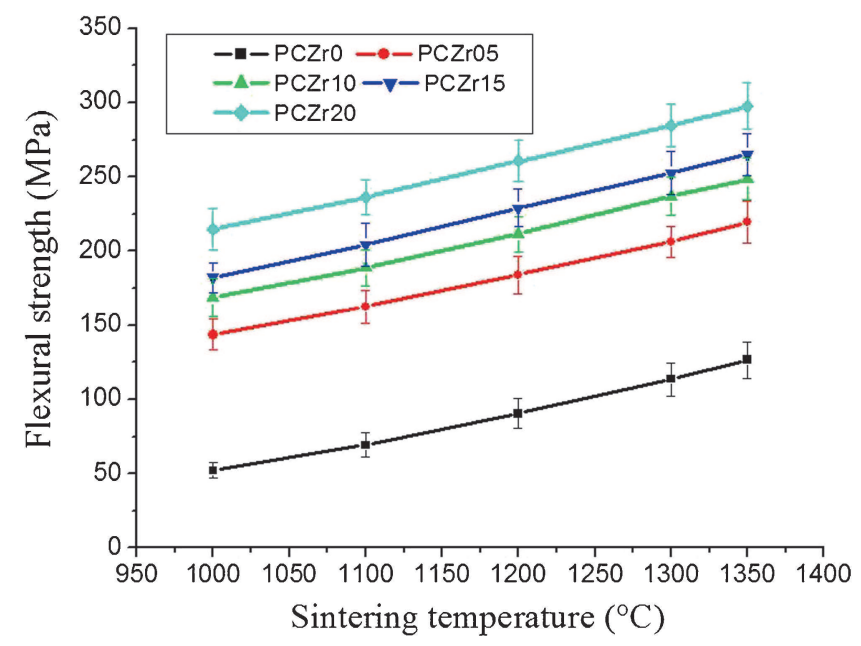

Figure 14. Flexural strength of pure cordierite and cordieritezirconia sintered at different temperatures.

zirconia. This shows that the fracture toughness value of ceramic for the addition of $20 \mathrm{wt} \%$ of $\mathrm{ZrO}_{2}$ was $3.94 \mathrm{MPa} \mathrm{m}{ }^{1 / 2}$. This research shows better than the fracture toughness by the indentation method, for the sintered bodies containing the various amounts of zirconia. The fracture toughness increased from 2.1 $\mathrm{MPa} \mathrm{m}{ }^{1 / 2}$ for pure cordierite to $3.2 \mathrm{MPa} \mathrm{m}{ }^{1 / 2}$ at a content of $35 \mathrm{wt} \%$ of $\mathrm{ZrO}_{2}$, which suggested that both the fracture strength and toughness depend on the amount and the phase type of zirconia. ${ }^{12}$

3.2e Testing for flexural strength: The data on the flexural strength of pure cordierite and cordierite-zirconia are shown in figure 14. The flexural strength of pure cordierite (PCZr0) ceramic samples were obtained for samples heat treated at various sintering temperature. The results reveal that the flexural strength of pure cordierite increases from 52.13 to $126.46 \mathrm{MPa}$ with the increase in sintering temperature, which may be due to the $\alpha$-cordierite formation at this temperature. ${ }^{12}$

The flexural strength of cordierite-zirconia ceramic (PCZr05-PCZr20) increased from 219.54 to $297.62 \mathrm{MPa}$ with the addition of $5-20 \mathrm{wt} \%$ of zirconia; this is shown in figure 14. It can be seen that the flexural strength increased gradually with the increase in zirconia content. Several toughening mechanisms may occur simultaneously in zirconia toughened composites. The stress-induced transformation from the tetragonal phase to the monoclinic phase is known as the most effective toughening mechanism for zirconia reinforced matrix ceramic composites. However, even if the martensitic transformation toughening mechanism will not prevail, other toughening mechanisms like microcrackingand crack deflection are expected to be active. The cordierite-zirconia presented an increase in strength up to $1350^{\circ} \mathrm{C}$. The observed results were found to be better than the previous research ${ }^{12}$ who studied the mechanical behaviour of cordierite-zirconia composites by co-precipitation process. The reported results show that the addition of $\mathrm{ZrO}_{2}$ to pure cordierite, increased the fracture strength from 110 to $260 \mathrm{MPa}$. The flexural strength were closely related to the microstructure and dependent on the amount and the phase type of zirconia (tetragonal or monoclinic).

3.2f Thermal expansion coefficient evaluation: The results for the cordierite $(\mathrm{PCZr} 0)$ samples show that the thermal expansion coefficient is $2.48 \times 10^{-6}{ }^{\circ} \mathrm{C}^{-1}$ at $70^{\circ} \mathrm{C}$ increases slightly to $4.08 \times 10^{-6}{ }^{\circ} \mathrm{C}^{-1}$ at $800^{\circ} \mathrm{C}$. The reason for this increase is due to the presence of cristobalite possibly formed by the crystallisation of amorphous silica. Coefficient of thermal expansion (CTE) of $\mathrm{CZr} 0$ measured showed that there is a little difference between the measured and reported. ${ }^{39}$

The thermal expansion coefficient increased from $0.52 \times 10^{-6}$ to $4.42 \times 10^{-6}{ }^{\circ} \mathrm{C}^{-1}$ for the cordierite-zirconia sample $(\mathrm{PCZr} 20)$ in the same temperature range. The addition of zirconia into the cordierite matrix increased the CTE monotonously. The slight increase of CTE for PCZr20 is due to the dispersion of $\mathrm{ZrO}_{2}$ in the cordierite matrix. As it is believed that the thermal expansion may be affected by the porosity content. The cordierite crystals with high porosity can cause expansion and contraction easily. This statement could explain why the thermal expansion of denser cordierite bodies are slightly higher than those with higher residual porosity. The CTE obtained for the composite was based on the sum of the coefficient of $\mathrm{ZrSiO}_{4}$ in the matrix and that of the cordierite matrix. ${ }^{15}$ The CTE of $\mathrm{ZrSiO}_{4}$ is $4.1 \times 10^{-6}{ }^{\circ} \mathrm{C}^{-1}$. Particles of larger CTE in a matrix of lower CTE cause thermal strain (tension), which results in the genesis of micro-cracks in the matrix around the particles. The results indicate that micro-cracks between the cordierite matrix and $\mathrm{ZrSiO}_{4}$ particles were generated during the first cooling, resulting in a decrease of thermal expansion.

\section{Conclusion}

From the results of the above study, conclusions drawn are as follows:

1. Pure cordierite and cordierite-zirconia (5-20 wt \%) under controlled composition was successfully synthesized.

2. Densified cordierite- $\mathrm{ZrO}_{2}$ was prepared by dispersing $20 \mathrm{wt} \%$ of zirconia at sintering temperature $1300^{\circ} \mathrm{C}$ and the addition of zirconia decreased the optimum sintering temperature at $1400^{\circ} \mathrm{C}$.

3. The fracture toughness of $3.94 \mathrm{MPa} \mathrm{m}^{1 / 2}$ with a hardness of $7.68 \mathrm{GPa}$ combined with a flexural strength of 297.62 MPa was observed in the cordierite-zirconia sample (PCZr20) that exhibited the highest value.

4. Addition of zirconia showed a better thermal expansion coefficient, a value which is considered to have a negligible effect on cordierite sample.

\section{Acknowledgements}

We would like to thank the Department of Mechanical Engineering, Anna University, Chennai 600025 and SMBS, VIT 
University Chennai 600127, India, for providing the facilities to carry out this research work.

\section{References}

1. Shamsudin Z, Hodzic A, Soutis C, Hand R J, Hayes S A and Bond I P 2011 J. Mater. Sci. 465822

2. Okada A 2008 J. Eur. Ceram. Soc. 281097

3. Williams J L 2001 Catal. Today 693

4. Trumbolic L J, Acimovic Z, Panic S and Andric L J 2003 FME Trans. 3143

5. Stoyanova D D, Vladov D Ch, Kasabova N and Mekhandzhiev D R 2005 Kinet. Catal. 46609

6. Kazakos A M, Komarneni S and Roy R 1990 J. Mater. Res. 5 1095

7. Pavlikov V M, Garmash E P, Yurchenko V A, Pleskach I V, Oleinik G S and Grigor'ev O M 2011 Powder Metall. Met. Ceram. 49564

8. Gibbs G H 1996 Mineral 511068

9. Montorsi M A, Delorenzo R and Verne E 1994 Ceram. Int. 20 353

10. Li P, Du Y and Hu L 2002 Refractory 36139

11. Zhou L, Wang C and Liu W 2009 Rare Met. Mater. Eng. 38 366

12. Hirano M and Inada H 1993 J. Mater. Sci. 2874

13. Senthil Kumar M and Elayaperumal A 2013 Int. J. Mater. Res. Technol. 799

14. Shu C, Mingia X, Cailou Z and Jiaqi T 2002 Mater. Res. Bull. 371333

15. Awano M and Takagi H 1994 J. Mater. Sci. 29412

16. Sun E H, Choa Y-H, Sekino $\mathrm{T}$ and Niihara K 2002 Ceram. Int. 6105

17. Ponton C B and Rawlings R D 1989 Mater. Sci. Technol. 5865

18. Djordjevi N and Pavlovi L 2006 J. Serb. Chem. Soc. 71293

19. Tang B, Fang Y W, Zhang S R, Ning H Y and Jing C Y 2011 Indian J. Eng. Mater. Sci. 18221
20. Pal D, Chakraborthy A K and Sen S 1996 J. Mater. Sci. 31 3995

21. Senguttuvan G, Settu T, Kuppusamy P and Kamaraj V 1999 J. Mat. Synth. Proc. 7175

22. Weikusat C, Glamacher U, Miletich R, Neumann R and Trautmann C 2008 Nucl. Instrum. Methods: Phys. Res. B 266 2990

23. Naskar M K and Chatterjee M 2004 J. Eur. Ceram. Soc. 24 3499

24. Janackovic D, Jokanovic V, Kostic-Gvozdenovic L, Zec S and Vskokovic D 1997 J. Mater. Sci. 32163

25. Radev L, Samuneva B, Mihailova I, Pavlova L and Kashchieva E 2009 Proc. Appl. Ceram. 3125

26. Hinklin T and Laine R 2008 Chem. Mater. 20553

27. Petrovic R, Janackovic D, Zec S, Drmanic S and KosticGvozdenovic L J 2003 J. Sol-Gel Sci. Technol. 28111

28. Saha S K and Pramanik P 1995 J. Mater. Sci. 302855

29. Valaskova M and Martynkova G S 2009 Chem. Pap. 63445

30. Goren R, Ozgur C and Gocmez H 2006 Ceram. Int. 3253

31. Vesteghem H, Di Giampado A R and Dauger A 1987 J. Mater. Sci. Lett. 61187

32. Higgins R I, Bowen H K and Giess E A 1987 In Ceramic powder science (eds) G L Messing, K S Mazdiyasmi, J W Mc Cauley and R A Haber (Columbus, OH, USA: American Ceramic Society) Vol 21, p 691

33. Mussler B H and Shafer M W 1985 J. Am. Ceram. Soc. Bull. 641559

34. Suzuki H, Ota K and Saito H 1987 J. Ceram. Soc. Jpn. 95 170

35. Travitzky N A and Claussen N 1988 Adv. Ceram. 23121

36. Niezery K and Weisskopf K L Petzow 1988 Sci. Sinter. 20149

37. Penkov I, Pascova R and Drangajova I 1997 J. Mater. Sci. Lett. 161544

38. Senthil Kumar M, Elayaperumal A and Senguttuvan G $2011 \mathrm{~J}$. Ovonic Res. 799

39. Yamuna A, Johnson R, Mahajan Y R and Lalithambika M 2004 J. Eur. Ceram. Soc. 2465 